High BMI(Obesity and Overweight) as a risk factor for increased incidence of miscarriage in pregnant women attending Emergency Department in Al- Batool Maternity Teaching Hospital - Baquba- Diyala Province

\title{
High BMI(Obesity and Overweight) as a risk factor for increased incidence of miscarriage in pregnant women attending Emergency Department in Al- Batool Maternity Teaching Hospital - Baquba- Diyala Province Semaa Nezar Adil $(\mathrm{MBChB})^{1}$ and Sawsan Talib Salman (FICMS, CABOG) ${ }^{2}$ Abstract
}

Background:Obesity has been known to be an obstetric risk factor because of the documented complications associated with it, and it is an indication for booking in a tertiary health institution.

Objective: To find if there is relation between high BMI (obesity or overweight) and risk of miscarriage.

Patients and Methods: This study was done in Al-Batool Maternity Teaching Hospital in Baquba City/ Diyala during the period from 1st of July 2016 to 28th of February 2017. Total number of 2500 were admitted during period of study, 105 of them fit inclusion criteria (pregnant for $\leq 22$ weeks of gestation and had signs and symptoms of miscarriage), divided into two groups (70 pregnant with high BMI women and 35 with normal BMI as control women), the two groups were matched for age and parity. Different parameters used to compare the risk of miscarriage between obese and control groups .

Results: Mean ages were $(25.02 \pm 5.78)$ years and $(25.8 \pm 5.83)$ for both high BMI group and control group respectively. Higher incidence of miscarriage was observed in high BMI women who living in urban area than control women living in the same area $(57.1 \%),(37.1 \%)$ respectively, and most of cases were house wives with high BMI (95.7\%) while (85.7 \%) was control group. Although the incidence of miscarriage was higher during the second trimester in high BMI women than control women but it is not statistically significant . This study shows no significant increase of miscarriage in a women with a previous history of miscarriage between high BMI group and control group .

Conclusion: High BMI pregnant women who lived in urban area had statistically significant increase risk of miscarriage, so good preconception care for those women to decrease their weight prior to pregnancy to avoid this complication .

Key words: BMI, Miscarriage, Urban area.

Corresponding Author: hajiasawsan@yahoo.com

Received: $3^{\text {th }}$ August 2017

Accepted: $28^{\text {th }}$ December 2017

https://doi.org/10.26505/DJM.

${ }^{1}$ Baquba Teaching General Hospital- Diyala- Iraq.

${ }^{2}$ Department of Obstetrics and Gynecology- College of Medicine- University of Diyala-Diyala-Iraq. 
High BMI(Obesity and Overweight) as a risk factor for increased incidence of miscarriage in pregnant women attending Emergency Department in Al- Batool Maternity Teaching Hospital - Baquba- Diyala Province

\section{Introduction}

Recently obesity considered the most common health threat in the western world, it has become the second leading cause of death in developed countries . previously only elderly people suffer from this disorder, but nowadays younger people are also affected. As a result, gynecologists will increasingly receive pregnant women suffering from overweight or (morbid) obesity [1] . Obesity can be defined as large amount of body fat, always lead to significant debilitation of health, there are approximately 300 million obese adults worldwide, Over weight and obesity are increasing overall the world, about 300.000 deaths per year may be attributable to obesity [2].

At present years, in association with increasing prevalence of obesity and overweight among people in developed countries, this make researchers concentrate on the relation between excessive pre pregnancy weight and obstetric complications [3]. Obesity are commonly affect women in reproductive age and is associated with multiple reproductive sequels, including anovulation, menstrual irregularity, infertility, miscarriage, and adverse pregnancy outcomes [4].

Obesity can be identified by using BMI (defined as $\mathrm{kg} / \mathrm{m} 2$ ) with the following classifications: "Underweight was defined as BMI less than 18.5, normal weight as BMI 18.5-24.9, overweight as BMI 2529.9, obesity BMI 30-34.9, and severe obesity as BMI 35 or higher"[5] . Obesity also considered as an independent risk factor for miscarriage, However, reports on the risk of miscarriage in obese women who conceive naturally are deficient and conflicting [6]. Maternal obesity adversely affects every stage of pregnancy and development [7]. several studies has been reported possibility of association between obesity and miscarriage and this may attributed to adverse effects on the embryo, the endometrium, or both [8].

Miscarriage defined as expulsion or extraction of an embryo or fetus from his mother weighing $500 \mathrm{~g}$ or less when it is not capable of independent survival (WHO). This $500 \mathrm{~g}$ of fetal development is attained approximately at 22 weeks of gestation. The expelled embryo or fetus is called abortus. The word miscarriage is the recommended terminology for spontaneous abortion[9].

There is evidence that not only obese women at increased risk of miscarriage if they conceive spontaneously but also if they are overweight [10]. Although many factors have been described to increase the risk of spontaneous miscarriage; but, the exact reason for the obesity-related increased risk of miscarriage is not known. The possibility of oocyte abnormality was opposed by a recent study of obese women who experienced a higher rate of spontaneous miscarriage after receiving oocyte donation compared with normal weight women, endometrial receptivity is so far another plausible explanation for early miscarriage, an un favorable intrauterine milieu associated with obesity is an 
High BMI(Obesity and Overweight) as a risk factor for increased incidence of miscarriage in pregnant women attending Emergency Department in Al- Batool Maternity Teaching Hospital - Baquba- Diyala Province

Semaa Nezar Adil

alternative explanation for the increased prevalence of miscarriage[11].

\section{Patients and Methods}

Cross- sectional study conducted in the Emergency Department of the Obstetrics and Gynecology in Al-Batool Maternity Teaching Hospital in Baquba City/ Diyala, during the period from 1st of july 2016 to 28th of February 2017, were total of 2500 admitted to the emergency department 105 patient fit the inclusion criteria( pregnant $\leq 22$ wks of gestation, had signs and symptoms of miscarriage, different parity, different education, different residency and both spontaneous and induced pregnancy) enrolled in this study who were classified into two groups . First group included high BMI women $\geq 25$. Second group included women who had BMI $\geq 18.5$ and $<25$ considered as control group, exclusion criteria ( underweight pregnant, unknown weeks of gestation, any medical illness such as hypertension,DM, PCOS and age $\geq 40$, pregnancy with abnormal fetus ) Weeks of gestation were calculated depending on the last menstrual period and 1 st trimester ultrasound. After took informed consent from them to participate in the study, an interview questionnaire was well designed and used for the collection of the relevant data which includes:The socio demographic characteristic of the pregnant women ( age , parity, weeks of gestation, last menstrual period, type of pregnancy wither it is spontaneous or induced, planned or not, socioeconomic and educational levels mode of delivery for each baby and the investigations) full examination and investigation done for each participant,. weight, height then body mass index ( BMI) were calculated.

\section{Statistical Analysis}

The $\mathrm{x} 2$ ( Chi-squared ) test method used to test theories on the differences between the percentages for qualitative data, so calculated ( mean and SD) for quantitative data. A level of significance ( 0.05 ) was applied to test. The statistics software used to process the data analysis were the ( spss v.20 ) program.

\section{Results}

Table (1) shown the mean age in high BMI group was $(25.02 \pm 5.78)$ while the meanage in control group was $(25.8 \pm 5.83)$.

Hemoglobin in high BMI group was ( 10.42 \pm 1.43 ) while in the control group was ( $10.20 \pm 1.57)$. Also the mean weeks of gestation in high BMI group was ( $13.13 \pm$ 4.89 ) while the mean weeks of gestation in the control group was ( $13.4 \pm 4.57$ ). 
High BMI(Obesity and Overweight) as a risk factor for increased incidence of miscarriage in pregnant women attending Emergency Department in Al- Batool Maternity Teaching Hospital - Baquba- Diyala Province

Semaa Nezar Adil

Table (1): General characteristics of studied group.

\begin{tabular}{||l||l||l||}
\hline \hline Parameters & High BMI & Control \\
\cline { 2 - 3 } & Mean \pm SD & Mean \pm SD \\
\hline \hline Age & $25.02 \pm 5.78$ & $25.8 \pm 5.83$ \\
\hline \hline Parity & $3.02 \pm 2.17$ & $1.428 \pm 1.420$ \\
\hline \hline Miscarriage & $2.04 \pm 1.42$ & $1.51 \pm 0.95$ \\
\hline \hline Hemoglobin(Hb) & $10.42 \pm 1.43$ & $10.20 \pm 1.57$ \\
\hline \hline Weeks of gestation & $13.13 \pm 4.89$ & $13.4 \pm 4.57$ \\
\hline \hline
\end{tabular}

In urban areas women with high BMI were significantly more likely to have miscarriage than control group at the same areas $(57.1 \%, 37.1 \%)$ respectively which was statistically significant $(\mathrm{P}-$ value $<0.05)$. Regarding the occupation, housewives with high BMI are more likely to have

Table (2): Socio-demographic factors in studied group.

\begin{tabular}{|c|c|c|c|c|c|}
\hline \multirow{2}{*}{$\begin{array}{l}\text { Parameters } \\
\text { Residency }\end{array}$} & \multicolumn{2}{|c|}{ High BMI } & \multicolumn{2}{|c|}{ Control } & \multirow[t]{2}{*}{ P- value } \\
\hline & No. & $(\%)$ & No. & $(\%)$ & \\
\hline Rural & 30 & $42.9 \%$ & 22 & $62.9 \%$ & \multirow[b]{2}{*}{$<0.05$} \\
\hline Urban & 40 & $57.1 \%$ & 13 & $37.1 \%$ & \\
\hline \multicolumn{6}{|l|}{ Occupation } \\
\hline House wife & 67 & $95.7 \%$ & 30 & $85.7 \%$ & \multirow{5}{*}{0.190} \\
\hline Nurse & 11 & $1.4 \%$ & 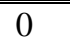 & $0 \%$ & \\
\hline Student & 0 & $0 \%$ & 1 & $2.9 \%$ & \\
\hline Teacher & 1 & $1.4 \%$ & 3 & $8.6 \%$ & \\
\hline Employer & 1 & $1.4 \%$ & 1 & $2.9 \%$ & \\
\hline \multicolumn{6}{|c|}{ Educational level } \\
\hline Collage & 2 & $2.9 \%$ & 4 & $11.4 \%$ & \\
\hline Diploma & 6 & $8.6 \%$ & 5 & $14.3 \%$ & \\
\hline
\end{tabular}

miscarriage ( $95.7 \%$ ) compared with control group ( $85.7 \%$ ). Also high BMI women of primary education are more likely to have miscarriage than control group of women $(75.7 \%, 57.1 \%)$ respectively as showed in Table (2). 
High BMI(Obesity and Overweight) as a risk factor for increased incidence of miscarriage in pregnant women attending Emergency Department in Al- Batool Maternity Teaching Hospital - Baquba- Diyala Province

Semaa Nezar Adil

\begin{tabular}{|c|c|c|c|c|c|}
\hline No education & 3 & $4.3 \%$ & 0 & $0 \%$ & \\
\hline Primary education & 53 & $75.7 \%$ & 20 & $57.1 \%$ & \\
\hline Secondary education & 5 & $7.1 \%$ & 6 & $17.1 \%$ & 0.105 \\
\hline
\end{tabular}

Table (3) reveals that there is higher group ( $73.5 \%)$ than control group incidence of miscarriage during the period $\quad$ (26.5\%) with no significant difference. (13- 18) weeks of gestation in high BMI

Table (3): Miscarriage rate studied group according to weeks of gestation.

\begin{tabular}{|c|c|c|c|c|c|}
\hline Weeks of gestation & \multicolumn{2}{|c|}{ High BMI } & \multicolumn{2}{|c|}{ Control } & P-value \\
\hline & No. & $(\%)$ & No. & $(\%)$ & \multirow{5}{*}{0.163} \\
\hline $1-6$ weeks & 6 & $75 \%$ & 2 & $25 \%$ & \\
\hline $7-12$ weeks & 24 & $53.3 \%$ & 21 & $46.7 \%$ & \\
\hline 13-18 weeks & 25 & $73.5 \%$ & 9 & $26.5 \%$ & \\
\hline $19-24$ weeks & 8 & $80 \%$ & 2 & $20 \%$ & \\
\hline
\end{tabular}

Table (4) showed that high BMI group with no history of infertility are of higher incidence of miscarriage ( $98.6 \%$ ) compared with control group (94.3\%)Also regarding history of miscarriage, history of two previous miscarriage in high BMI group is of higher incidence than control group ( $25.7 \%, 20 \%$ ) respectively but all of these findings not significant. 
High BMI(Obesity and Overweight) as a risk factor for increased incidence of miscarriage in pregnant women attending Emergency Department in Al- Batool Maternity Teaching Hospital - Baquba- Diyala Province

Semaa Nezar Adil

Table (4): Miscarriage rate in studied group according to different obstetrical parameters.

\begin{tabular}{|c|c|c|c|c|c|}
\hline \multirow{2}{*}{$\begin{array}{l}\text { Parameters } \\
\text { Type of pregnancy }\end{array}$} & \multicolumn{2}{|c|}{ High BMI } & \multicolumn{2}{|c|}{ Control } & \multirow[t]{2}{*}{$\mathrm{P}$ - value } \\
\hline & No. & $(\%)$ & No. & $(\%)$ & \\
\hline Spontaneous & 68 & (97.1\% & 34 & $97.1 \%$ & \multirow[b]{2}{*}{1.00} \\
\hline Induced & 2 & $2.9 \%$ & 1 & $2.9 \%$ & \\
\hline \multicolumn{6}{|l|}{ History of infertility } \\
\hline No & 69 & $98.6 \%$ & 33 & $94.3 \%$ & \multirow[b]{3}{*}{0.318} \\
\hline Primary & 1 & $1.4 \%$ & $\overline{c 1}$ & $2.9 \%$ & \\
\hline Secondary & 0 & $0 \%$ & 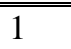 & $2.9 \%$ & \\
\hline \multicolumn{6}{|l|}{$\begin{array}{l}\text { History of previous } \\
\text { miscarriage }\end{array}$} \\
\hline 1 miscarriage & 33 & $47.1 \%$ & 24 & $68.6 \%$ & \multirow{7}{*}{0.191} \\
\hline 2 miscarriages & 18 & $25.7 \%$ & 7 & $20 \%$ & \\
\hline 3 miscarriages & 12 & $17.1 \%$ & 2 & $5.7 \%$ & \\
\hline 4 miscarriages & 3 & $4.3 \%$ & $\overline{c 1}$ & $2.9 \%$ & \\
\hline 5 miscarriages & 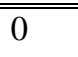 & $0 \%$ & $\overline{c 1}$ & $2.9 \%$ & \\
\hline 6 miscarriages & 3 & $4.3 \%$ & 0 & $0 \%$ & \\
\hline 8 miscarriages & 1 & $1.4 \%$ & 0 & O\% & \\
\hline
\end{tabular}

\section{Discussion}

In this study high BMI group $(\geq 25)$ revealed higher rate of miscarriage was found in pregnant with high BMI and $\geq 21$ years of age compared with control group , this agree with Jim et al ( 2001 ) who found that age $\geq[30$ years in obese women were more prone to miscarriage [12], this may be because new trend in our society that young people take care more about their elegance even during pregnancy this lead to decrease rate of obesity in this age group, while disagree with Per et al (2011) who said that there is no significance difference in age groups between obese and overweight and normal weight women [ 5 ]. There is no significant difference were observed in this study between women with high BMI and control group regarding parity, this agree with Madiha et al ( 2005 ) who concluded the same findings [ 2 ], while disagree with Mariana et al ( 2014 ) 
High BMI(Obesity and Overweight) as a risk factor for increased incidence of miscarriage in pregnant women attending Emergency Department in Al- Batool Maternity Teaching Hospital - Baquba- Diyala Province

Semaa Nezar Adil

who found that miscarriage was higher in women who had 2-3 children[ 13 ].

Previous history of miscarriage had no significant difference between the studied group, this may be due to limited time of collection of data, this agree with Rittenberg et al ( 2011 ) [ 10 ], while disagree with Mostafa et al ( 2010 ) who concluded that a mild increase in the BMI do not increase the risk of miscarriage but high BMI will increase the risk of miscarriage in the subsequent pregnancy, this may be related to the role of leptin increase with increase in BMI wich of beneficial effect that it increased endometrium receptivity but with high increase in BMI this lead to leptin resistance and deficiency that lead to increase risk of miscarriage [8] .

In this study, the decrease in hemoglobin level after miscarriage was not significantly different between women with high BMI and control group, this may be due to active management of miscarriage and early counseling of hospital with any symptoms suggestive of bleeding due to good prenatal education regarding warning symptoms of pregnancy in our province. This agree with Ovesen et al ( 2011 ) [ 5 ].

Although this study found that miscarriage at gestational age between (13 - 18) weeks is higher in high BMI group than control group but it was statistically not significant compared with other weeks of gestation this may be because most of cases of miscarriage was ended completely at home in earlier weeks of gestation and not recorded. This result agree with Murphy et al ( 2012 ) who found that there was no relation between weeks of gestation and more complications in higher BMI [14].

This study found that there is significant increase in the rate of miscarriage in women with high BMI lived in urban than rural area and these findings higher than control group who lived in the same area, this may be related to that most of women who admitted to hospital in period of study were from urban areas or may be increase rate of overweight and obesity among women lived in urban areas, this agree with Eden et al (2013) [15].

Primarily educated(high BMI) women in this study had higher rate of miscarriage than control group, although there is no significant difference but this could be explained that primarily educated women tend to had large families so this lead to frequent pregnancy and miscarriage or may be because of lack of awareness of health care in our society and low educational level of most of our patient that make them not take care of their health during pregnancy. This disagree with Mustafa (2015) who found that higher levels of education was a risk factor for increase rate of miscarriage in obese women [16] .

Miscarriage increased in this study among high BMI housewives comparing with workers women of control group but it was statistically not significant. This result not 
High BMI(Obesity and Overweight) as a risk factor for increased incidence of miscarriage in pregnant women attending Emergency Department in Al- Batool Maternity Teaching Hospital - Baquba- Diyala Province

Semaa Nezar Adil

in concordance with Sunil ( 2011 ) who found that worker women aborted their fetuses more than housewives [17 ] . This result in our study may be due to difference in communities regarding habits and traditions that made women prefer to be housewives than to be a worker outside her home .

Although there number of miscarriage reported to be higher in studied group and previous history of infertility than control group but statistically not. this result disagree with Jose et al( 2003) who found that early miscarriage highly reported in obese women with history of infertility[18], this may be because of small sample size in this study comparing with other studies .

\section{Conclusions}

High BMI pregnant women who lived in urban area had statistically significant increase risk of miscarriage, so good preconception care for those women to decrease their weight prior to pregnancy to avoid this complication.

\section{References}

[1] Johannes J, and Duvekot . Pregnancy and obesity: practical implications . Eur Clinics Obstet Gynaecol 2005; 1: 74-88.

[2] Madiha M, Tosson, Tarek K . The impact of maternal obesity on pregnancy outcome at assiut university hospital. Ass. Univ. Bull. Environ. Res. 2005; 8(2):1-11 .

[3] Wieslaw M . Maternal underweight and pregnancy outcome: prospective cohort study . Archives of perinatal medicine. 2007; 13 (3): $23-26$.
[4] Emily S , Jennifer L, and Margaret M . Weighing the impact of obesity on female reproductive function and fertility. 2013 ; 71( 1):S3-S8.

[5] Ovesen P, Rasmussen S, Kesmodel U. Effect of prepregnancy maternal overweight and obesity on pregnancy outcome. Obstet Gynecol. 2011 ;118(2):305-12.

[6] Kristina A, Qing Q, Andrée G . Obesity in Pregnancy: Pre-Conceptional to Postpartum Consequences . J Obstet Gynaecol Can 2008; 30(6):477-488.

[7] Claire Fm and Woodworth B. Tipping the Scale: Reframing Maternal Obesity as Obesity Commentary. Mcmaster University Medical journal. 2015; 12 ( 1 ):32-34|.

[8] Mustafa M, Sotirios H, William L, Phil $\mathrm{D}$, and Tin C . Body mass index and risk of miscarriage in women with recurrent miscarriage. Fertility and Sterility.2010; 94( 1):290-295.

[9]Dutta's D. Hemorrhage in early pregnancy.8th Ed. DC Dutta'a Texbook of Obstetrics including Perinatology and Contraception.2015:pp 185-231.

[10] Vivian R , Sviatlana S, Alyaa A, Eugene O, Virginia B, Yacoub $\mathrm{K}$, et al. Influence of BMI on risk of miscarriage after single blastocyst transfer. Human Reproduction. 2011; 0(0):1-9.

[11]Lashen H,Fear K, and Sturdee D . Obesity is associated with increased risk of 1 st trimester and recurrent miscarriage: matched case \pm control study. Human Reproduction. 2004; 19( 7 ):1644-1646. 
High BMI(Obesity and Overweight) as a risk factor for increased incidence of miscarriage in pregnant women attending Emergency Department in Al- Batool Maternity Teaching Hospital - Baquba- Diyala Province

Semaa Nezar Adil

[12]Jim X, Michael J, and Robert J . Obesity Increases the Risk of Spontaneous Abortion during Infertility Treatment. Obesity research. 2002;10( 6) :551-554.

[13] Mariana S , Fernanda P , Jaime J , Eduardo V and Gustavo V. Maternal obesity and fetal deaths: results from the Brazilian cross-sectional demographic health survey, 2006 . BMC Pregnancy and Childbirth 2014; 14:5.

[14]Murphy L , Thornburg L , Glantz J , Wasserman E, Stanwood N, Betsadt S. Complications of surgical termination of second trimester pregnancy in obese versus non obese women . $2012 ; 86(4): 402-6$. [15]Eden R , Tanaka J , Lisa M , Maureen E, Geraldine E, Randall B, et al. Knowledge of Obesity and Its Impact on Reproductive Health Outcomes Among
Urban Women. J Community Health. 2013 ; 38(2): 261-267.

[16] Mustafa A . Prevalence of Abortion and Contraceptive Practice among Women Seeking Repeat Induced Abortion in Western Nigeria . Journal of Pregnancy. 2015 ; Article ID 486203, 7 pages .

[17] Sunil K . occupational , environmental and life style factors associated with spontaneous abortion . $2011 ; 18$ (10) . [18] Jose' B , Luis P , Ernesto B, Andre' s $\mathrm{Z}$, Jose' $\mathrm{T}$,Fernando $\mathrm{M}$, et al. Obesity and the risk of spontaneous abortion after oocyte donation. Fertility and sterility. 2003; 79 (5):1136-1140. 